\title{
Knowing How to Act Well in Time
}

\author{
Peter Wagner (1D
}

Received: 16 April 2020 / Accepted: 3 August 2020

(C) Journal of Bioethical Inquiry Pty Ltd. 2020

\begin{abstract}
Numerous scholars in the social sciences and humanities have speedily analysed and interpreted the COVID-19-induced social and political crisis. While the commitment to address an urgent topic is to be appreciated, this article suggests that the combination of confidence in the applicability of one's tools and belief in the certainty of the available knowledge can be counterproductive in the face of a phenomenon that in significant respects is unprecedented. Starting out from the plurality of forms of knowledge that are mobilized to analyse COVID-19 and its consequences as well as the lack of any clearly hegemonic knowledge, the article tries to understand how a limited convergence in the politico-medical responses to the crisis emerged, and speculates on what would have happened if this had not been the case. In conclusion, it is argued that this pandemic demands a greater awareness of the uncertainty of our knowledge and of the consequences of our actions, both in terms of being situated in time and of aiming at timeliness.
\end{abstract}

\footnotetext{
P. Wagner

Catalan Institute for Research and Advanced Studies (ICREA), Barcelona, Spain

P. Wagner

Ural Federal University, Yekaterinburg, Russia

P. Wagner $(\bowtie)$

Department of Sociology, University of Barcelona, Av. Diagonal, 690, E-08034 Barcelona, Spain

e-mail: peter.wagner@ub.edu
}

Keywords Action - Covid-19 - Democracy Knowledge $\cdot$ Pandemic $\cdot$ Technocracy $\cdot$ Time . Uncertainty

There is no shortage of analyses and interpretations of the crisis that the COVID-19 has inflicted on humankind and of its consequences. As it seems, many of my colleagues in the social sciences and humanities only had to take out their toolkit and put it to use on this new phenomenon. At times, one could even have the impression that they were waiting for something like this to happen for them to rush to go public with their analyses and proposals.

Characteristically, the interpretations of the crisis come in two forms. The optimists hold that humankind will grow through this experience. The world after COVID-19 will show more solidarity, moral commitment, and concern for the common good. The era of unrestrained profit-making, boundless pleasure-seeking, and selfish pursuit of one's goals without concern for others will come to an end. These observers call for action to grasp the unique occasion for creating a better world, unique because, for once, the world is already moving in that direction. In turn, the critics observe a crisis-driven move to authoritarianism, to new nationalism and restrictions to movement, to technocracy with political decisions based on expertise rather than deliberation, in short, the return to disciplinary society combined with isolation of individuals and loss of sociality. The short era of liberal democracy and convivial civil society during which the power of dominating groups 
could effectively be limited will come to an end. These observers call, if they do, for resistance, and their view is marked by suspicion and denunciation of the politicians and their advisors whom we see and hear every day now.

Faced with this avalanche of striking analyses, I have asked myself: why do I not have anything to contribute to this debate? It's not that I lack the impetus. Like many others, I have the impression to experience a sociopolitical event of possibly greater significance than any other during my lifetime. And as someone who studies society, history, and politics, I feel I should have something to say on this event. And if so, I should say so loudly, to be heard. So, why don't I?

Helped by the postponement of other commitments due to the lockdown, at the time of writing (mid-April 2020) already in its fifth week in Spain where I live, I collect as widely as possible information on the ongoing events but also on their background and their conditions. Thus, despite not having specific medical expertise, I do not feel that I know too little - too little in the sense of knowing so much less than others that I should keep my mouth shut. Rather, I feel that we all know too littletoo little to be certain to act well, as far as the politicians and medical advisors are concerned, and too little to understand well what the appropriate action is, as concerns all others, for most of us.

This lack may be exactly that which is most characteristic of the current situation. COVID-19 emerged at a moment when, despite evident and accumulating signs to the contrary, the view was still widespread that we have all the knowledge we need and all the required understanding for necessary action; that things are basically under control or can at least be brought under control; and that this control emerges as the aggregate outcome of uncoordinated action rather than through communication and coordination among those affected and involved. This is a view that our current "modernity" is largely built on. COVID-19 shakes the building and imposes a reflection on our assumptions about knowledge, action, and time. What follows is a small step in that direction.

\section{Plural Sources of Knowledge}

Epidemiology and virology, so I learnt quickly, were expecting something like this to happen. They have accumulated knowledge of considerable quality and coherence, dating back at least to the influenza pandemic of 1918-1920 (still known as the Spanish flu; a century ago, such an inadequate naming could still be made to stick) and building up in concise terms with HIV, SARS, H1N1, Ebola, and MERS across the past few decades. The problem, though, is that every virus is specific and the behavioural properties of this one were unknown and are still not sufficiently known. They can be understood only through observation, after it already emerged. While comparing COVID-19 with its predecessors could usefully guide research, drawing conclusions from quickly made comparisons could easily mislead — or delay - remedial action.

In the next step, the gradually increasing knowledge about the virus is confronted with two other kinds of knowledge. On the one side, techniques of mathematical modelling have considerably developed in recent time. They are at the forefront of attempts at trying to understand uncertain futures. They have a prominent place in the deliberations of the International Panel on Climate Change (IPCC), and for good reason, since without them little would be understood at all. But public debate-and already preceding it, public science communication-tends to forget about the degree of uncertainty. With regard to climate change, a reasonable maxim for action can rather easily be devised: it is better to err on the side of prudence. With regard to covid-19, conclusions are less straightforward. Among other institutions, the Institute for Health Metrics and Evaluation (IHME) at the University of Washington has become widely known for its predictions of covid-19 infections and deaths in the United States and elsewhere. Reasonably, the researchers steadily update their findings - and their modelling - by introducing new data. As a consequence, though, their predictions are corrected day by day, and they change by considerable margins. Rather than orienting public debate and action, their effect is disorientation. It might be advisable to refrain from publishing these figures - even though this would less be a call on the researchers, who will wish to enhance timely scholarly collaboration, rather than on the media, which at the very least could underline the extremely fragile nature of this knowledge.

On the other side, neither the virus nor mathematics know anything about institutions. But the number of medical doctors, nurses, intensive care units, personal protection equipment, and their distribution and availability across space and time is crucial for the development of the pandemic and for the chances of slowing it 
down or stopping it. This is knowledge that public health research can provide, but the recommendations that follow from it may be quite different from those that would be arrived at when relying only on epidemiology, virology, and mathematical modelling. There is evidence that such a knowledge clash occurred over COVID-19, more pronounced in the early weeks of the pandemic, and in some countries, in particular in the United Kingdom and Sweden, with more consequences than in others.

Governments all across the planet claim that their COVID-19 policies are "science-based." Heads of government and ministers of health appear always accompanied by leading medical experts in their press conferences. Some observers have seen this as a sign of an emerging new technocracy, with expertise overriding democratic deliberation. Given the multiple kinds of knowledge, however, this seems far from the case. Let us look at two earlier political uses of scientific expertise in comparison.

\section{Prior Cases of Knowledge Hegemony}

After the Second World War, the slogan about the "civilian use of nuclear energy" promised a radiant future based on an endless supply of cheap energy and, consequently, infinite growth of the wealth of all nations with guaranteed satisfaction of every material need. Science seemed truly to have become the "endless frontier." It took considerable time and effort to change public debate by underlining not only the danger of operating nuclear power stations but also the hubris of claiming to control nuclear waste sites over millennia to come. This was gradually achieved by the late 1970 s, and the transformation of the debate was not least due to the elaboration of counter-expertise of such a scholarly quality that it could no longer be easily rejected or ignored.

At about the same time, the late 1970s, a shift in hegemony occurred within the economic sciences. As Keynesian demand management seemed to have failed to effectively respond to the economic problems of the early 1970 s, a return to more conventional versions of neo-classical economics happened, which in policy terms demanded the reduction of public debt, of labour cost, and of taxation of profits, supposedly to unleash again the beneficial workings of markets. The new policies clearly benefitted certain business interests and worked against the less well-off in society. In this light, it remains a bit of an enigma why also centre-left (social democrat) politicians complied with this new doctrine, but what we may call epistemic domination certainly played a role: the economic sciences claimed to have understood why earlier policies failed and, based on these insights, arrived at an apparently clear view of the unalterable laws of market economies. In this case, there was a preceding "counter-expertise," but it was discredited by having failed to avert crises.

In both of these cases, therefore, there was a monopoly or hegemony of expertise, and the recommendations following from such expertise served powerful interests in society, served (parts of) the dominating groups, as one used to say. The critical theories of technocracy, as they were elaborated during the 1960s and 1970s, were based on observations of such a situation. But none of this is characteristic of the present moment, for at least two reasons.

\section{Slow and Unstable Convergence of COVID-19 Knowledge}

First, whatever there is in terms of hegemonic expertise is of a different nature. One may say that, after all, most governments follow the guidelines for dealing with pandemics that had been elaborated by the World Health Organisation (WHO) and the respective national institutes of health. But in contrast to the physics of nuclear energy and the claims of neo-classical economics, the knowledge of a pandemic requires detailed and nuanced empirical observation of the specificities of the situation. As said above, this kind of knowledge only becameand still becomes - gradually available. Furthermore, this knowledge is then liable to somewhat different interpretations by epidemiology, virology, modelling, and public health. At the moment of writing, one can say that there has been a considerable, even though in some settings slow, process of convergence of knowledge-based policy recommendations over the first few months of the pandemic. This convergence may even be understood, optimistically, as an indicator of solidarity across borders, or some understanding of a common problem and the need to act in common. But such convergence is not yet assured for the further course of the pandemic and the measures for "deescalation." 
This is so because, second, the already plural set of bio-medical expertise, broadly understood, meets countervailing expertise from the social sciences-economics, sociology, political science, psychology - as soon as policy decisions need to be taken. This is not to say that truly scholarly knowledge from these disciplines was present at the beginning, not at all. But politicians have a kind of "practical expertise" in these matters. They have a sense of their dependence on the mood in circles of society: business circles, the media, social movements, and others, varying with the political parties. This "knowledge" tells them what they can do and not do. From this observation, two questions arise, one asking about the decisions regarding the past two months and one asking about the decisions to be taken during the next, say, half a year.

\section{A Short Counter-Factual Speculation}

The striking answer to the first question is that politicians have done what they knew could not be done, namely ordering what is now called a "lockdown" of economy and society. The two societies that have long (though in recent years much less) been seen as the standard-bearers of liberalism, the United Kingdom and the United States, toyed for some time with taking another route, led by governments that incarnate the doubt about institutional collective action that has become more widespread across the past three decades in general (more surprisingly, and probably for somewhat different reasons, Sweden did so as well). This initial divergence permits us to speculate about what would have happened if this laissez aller had become the dominant attitude. Clearly, many more people would have died, and at some point "herd immunity" would possibly have been reached-from all we know now: very little and after many victims. The pandemic would have been described as a natural catastrophe, like a giant earthquake or a tsunami. The governments would have regretted the "human losses" but argued that there was nothing that could be done about them-or at least nothing that could reasonably be done, given that different concerns had to be balanced. Such an attitude was not as widely off the mark as it seems in the current moment, since concerns about restrictions of civil liberties and human rights have been and keep being voiced in many countries. We will know better only much later, but it is possible that only the emerging concise view of the WHO at the core of a well-networked global epistemic community in health studies prevented this option from being pursued and forced initially deviating governments to fall in line.

Carrying the speculation one step further, it is likely that we would talk very differently about COVID-19 if that road had been taken. The pandemic would have been placed in the line, sketched above, that leads from the "Spanish flu" to more recent spreads of viruses and just be compared in quantitative terms: number of infections and deaths, spatial diffusion, time until development of a vaccine or a treatment. There would have been some debate about social consequences, such as the sudden loss of the older generation, comparable with the debate about HIV/AIDS and changes in sexual behaviour. This would have been a "crisis," to be sure, but one that would have been cognitively domesticated by analysing it as something that had already happened before, only in describably different form.

\section{The Unprecedented "Lockdown" and the Difficulty of Imagining Futures}

If so, then it is the extended "lockdown" that marks the difference, because of the sudden and radical halt to most economic, social, and cultural activities. It is the reason why we talk about COVID-19 as potentially leading to a radical social transformation in a way in which we did not do about any of the other diseases mentioned above, except in some limited respects for HIV/AIDS. This halt, though, is nothing like an earthquake or a tsunami. It has been decided by governments and implemented by public administration, even supported by the deployment of the states' monopoly of legitimate violence. At times, the current situation is compared to a war. But recent experience of extended warfare, in particular the two world wars of the twentieth century, meant the total mobilization of society for the purpose of winning the war. Currently, some segments of society are extremely highly mobilized, most importantly health workers, but most of society has been forced into de-mobilization. This is what is unprecedented and appears to us as a harbinger of radical change.

Since the financial crisis of 2008 , critical political sociology has re-focused its attention on the relation between capitalism and democracy. One influential interpretation holds that governments today have to address two constituencies: the people in the traditional 
sense of the citizenry, expressing itself through elections and opinion polls, on the one hand, and on the other hand, the global markets, granting or withdrawing credibility and, as an immediate consequence, resources to indebted states (e.g., Streeck 2013). When there is tension between the interests of the constituencies, so the argument goes, the market constituency tends to prevail. Currently, though, governments appear to act against the interests of both of these constituencies: they have wiped out the profit-making opportunities of big business and the earnings of small business and selfemployed workers; they have forced workers into unemployment, most drastically those in informal work situations; they have closed down the consumption and leisure activities that were considered sacrosanct because they kept people content (for an early attempt of analysing the dynamics of financial-crisis management, see Tooze 2020). Pre-COVID-19 political sociology is at a loss to explain such government action.

At first sight, one plausible way to close the explanatory gap is to underline that these measures are temporary, that they are taken in an emergency, that everything will return to "normal" once the emergency is over. But this leads us to the second question, the one about the decisions that will be taken in the near future. In parallel to the mathematical modelling of the course of the pandemic, economic modellers shoot figures about the expected decline in economic growth and its duration. However, in this situation even more than before, rather than being based on sound knowledge and technique, these predictions are best seen as attempts to imagine futures in the hope that the imagination will guide action in such a way as to make the future less uncertain than it actually is (Beckert 2016).

It cannot be ruled out that, some time from now, something like a return to "normality" will occur. The adjustments of institutions and practices may turn out to be small compared to some of the expectation and imagination that the current exceptionality has generated. At the current moment, however, uncertainty and lack of knowledge prevail. And it is under this angle that the entire crisis is most fruitfully analysed.

\section{When Is Action Late?}

In many countries, governments have recently been criticized for having reacted late and insufficiently to the emergence of COVID-19. While such criticism is more valid in some cases than others (and what follows should not be read as exempting everyone from responsibility), it is very often based on a problematic use of temporality. It is argued that some piece of information had been available early but that the action that was the adequate response to the information was taken with a considerable delay. It is overlooked that it was only with hindsight that the information was seen as requiring a certain action, not at the moment it first emerged. The criticism assumes, on the one hand, a timeless certainty of knowledge. By implication, it also assumes a fundamental stability of the world, in which an occurrence in the present can only be a repetition, with at best minor and insignificant alteration, of an occurrence in the past. And on the other hand, it assumes an unquestioned hierarchy in the application of knowledge, namely to be effected by the state. In other words, the criticism operates with a kind of vulgar platonism, a timehonoured desire of human beings to have everything known and under control.

The first assumption holds that the knowledge required for action is in principle available; and that actors who do not avail themselves of the required knowledge are at fault. But this is in denial of exactly that which many of us experience, namely the occurrence of something unprecedented, and thus the lack of actionadequate knowledge. In the light of uncertain knowledge, and furthermore of a knowledge base that was only evolving over time, politicians have hesitatedproblematically so but also understandably.

For purposes of action, the novelty does not have to be absolute to be problematic. Virologists are unlikely to see COVID-19 as radically different from all other viruses, and even sociologists do not need to abandon all of the concepts they developed for social transformations. We only need to be ready to accept that the novelty of the current situation is such that the knowledge-at-hand is insufficient to adequately understand it; that this situation is not one that can be easily subsumed under the concepts we are used to employ. Therefore, it is more important at the moment to observe closely, to try to describe, to look for possible comparisons, probably not any single one that explains everything, but many partial comparisons. And this requires time. But if our scholarly knowledge is not sufficient for fully and immediately understanding the COVID-19induced situation we are in, we also have to accept that the situation is similar for those who have responsibility to act. It is, furthermore, made much more difficult by 
the fact that the adequacy of an action often depends on whether it was made in time.

\section{The Capacity of Acting Well in Time}

The question of adequacy in time leads to the second assumption, the one of state capacity. In this regard, the virus encountered our societies on the wrong foot. The idea that the aggregate of uncoordinated individual actions would on its own bring about desirable outcomes has been ever more widely accepted for decades, in as different areas as unregulated market exchange, the "non-governmental" workings of "civil society," and the clip-form of communicative exchange in global social networks. In some such cases, like a stock exchange movement, a crowd-funding initiative, or a social-network clip "going viral," this kind of "collective" action can today be extremely fast, can take the form of a "social avalanche" (Borch 2019). With more such phenomena, though, the doubts about the presupposed desirability of the outcomes also increase.

In contrast to those phenomena, co-ordinated collective action, based on problem-oriented communication and sedimented in purpose-guided institutions, has been systematically discredited for over three decades. Many of its sites have been weakened and dismantled, in some cases as concretely as in the authority and resource endowment of public-health institutions. Such institutions were supposed to be slow both in receiving new information and knowledge and in acting efficiently on the basis of such information. Ironically, such recent criticism of bureaucratic states mirrors the timehonoured objections to pluralistic democratic deliberation, supposed to be incapable to confront any urgencies. However, we have no reason to believe that action based on multiple advice and plural deliberation is necessarily slower than either so-called "self-regulation" or hierarchic technocratic action (Flaig 2013).

There is no reason at all to glorify currently leading politicians. Most often, their reasons for acting tend to be considerably less than noble: getting re-elected; not offending their main allies in society; having something plausible to communicate in the short term. They are not necessarily oriented towards, as their "vocation" (Weber 1994 [1919]) should be, the common good or the benefit of society at large. But watching them these days, we see that they do not even know how to pursue their lessthan-noble objectives: their re-election prospects are highly uncertain; they have acted against the immediate interests of their clientele; they are at a loss of communicating anything very convincing. As said above, they all claim that what they do is "science-based," but they say so merely to provide a justification that they would otherwise lack. There is hardly an indication of a rising technocracy and/or of a new form of authoritarian control.

Suddenly, critics expect this systematically disabled state to get everything right, and immediately. What we observe, though, is rather the evidence of lack of control and even of the illusion of control that politicians are used to advertise because it comes with their office. Today, politicians are weak in the face of both, the pandemic and the criticism of how they are handling it. Clearly, they do not have the tools at hand that they would have had before austerity politics and the discrediting of collective institutional action. And having lost those (or rather: thrown them away), they also now face human and civil rights-based criticism for wanting to increase the monitoring of behaviour; business criticism for destroying a functioning economy; social criticism for disregarding the fate of those who are less well off; and more.

\section{Being-in-Time and Timeliness}

Rather than orienting our social-science analyses towards sorting out which criticism is most justified, and to determine "whose side we're on," it seems to me we should grant to those responsible for action that they encounter the same uncertainty as everyone else in the face of a situation that in crucial respects is unprecedented. The difference between "them," the politicians, and "us," the scholars, but also between politicians in office and those in opposition, is that that the former need to act in time - and with regard to COVID-19 indeed with considerable urgency. Social scientists, most of the time, are exempted from that obligation. As social scientists, though, their obligation would be to elaborate a knowledge of society, economy, and politics that takes uncertainty and temporality better into account to understand the conditions for action in time.

Such knowledge will always be difficult to achieve but we can at least briefly spell out what, for want of better terms, can be called an ontological attitude and a methodological maxim. With regard to the former, one should abandon the notion that social phenomena repeat 
themselves. This is not even true of viruses, as COVID19 in relation to other coronaviruses shows, and much less so for social phenomena. Rather than looking for regularity and equilibria, as much social science does, it is often more useful to focus on moments of imbalance, asymmetry, dispute, which is when more of the social world and its dynamics reveals itself (see, e.g., Boltanski 1990).

This attitude has consequences for the pursuit of two of the most common activities of the social sciences, namely trying to derive the present from the past and predicting the future. As to the latter, as mentioned above, a key technique is mathematical modelling, developing with great speed and considerable variety. Its practitioners are mostly well aware of the uncertainty they are dealing with. But they rarely convey this in public and, at least as importantly, they try to reduce uncertainty mostly by feeding in more data and improving technique. Thus, remedial action with regard to past errors is again done by forward-looking. More effort may need to be devoted to review past modelling exercises and the way their-social, not just mathematicalstatistical - assumptions may have created or exacerbated erroneous predictions. ${ }^{1}$

The future is not merely an extrapolation of the present, as the present is not an extrapolation of the past. But in contrast to the future, the past has for us the advantage that something about it is known with some degree of certainty, notwithstanding all ongoing dispute in the theory and philosophy of history. We have to learn to relate to the past in such a way as to grasp the possibly common conditions for action without limiting our current possibilities to the existing range of past outcomes. With a specific issue in mind, such as COVID-19 today, the first question concerns the identification of a comparable situation. This is neither the plague, because the social configuration was very different, nor SARS, because the behaviour of the virus was very different. My intuition is that a COVID-19oriented historical-comparative sociology could fruitfully look at the First World War and the 1918-1920 pandemic. A century ago, societies were not so different from present ones that an attempt at comparison would find too little to hold on to. This is the minimum condition for a fruitful comparison. Furthermore, those societies had undergone a major social transformation in the decades before 1914, one that today is sometimes called a first globalization. The dynamics of this transformation led towards catastrophe; and when the virus emerged, the catastrophe of the First World War had already happened. Today, COVID-19 may have emerged just in time for us to avert catastrophe- - a future catastrophe that does not yet have a name but several candidates of which climate change is arguably the front-runner.

My apologies for having turned a conclusion into a new opening. My excuse is that maybe this is just what we need to do.

\section{References}

Beckert, J. 2016. Imagined futures: Fictional expectations and capitalist dynamics. Cambridge, Mass.: Harvard University Press.

Borch, C. 2019. Social avalanche: Crowds, cities, and financial markets. Cambridge: Cambridge University Press.

Boltanski, L. 1990. L'amour et la justice comme compétence. Paris: Métailié.

Flaig, E. 2013. To act with good advice: Greek tragedy and the democratic public sphere. In The Greek polis and the invention of democracy: a politico-cultural transformation and its interpretations, edited by J.P. Arnason, K.A. Raaflaub, and P. Wagner, 71-98. Oxford: Wiley-Blackwell.

Streeck, W. 2013. Buying time: The delayed crisis of democratic capitalism. London: Verso.

Tooze, A. 2020. How coronavirus almost brought down the global financial system. The Guardian, April 14. https://www. theguardian.com/business/2020/apr/14/how-coronavirusalmost-brought-down-the-global-financial-system. Accessed April 14, 2020.

Weber, M. 1994 [1919]. Politik als Beruf. In Studienausgabe der Max-Weber-Gesamtausgabe, vol. 17, edited by W.J. Mommsen and W. Schluchter. Tübingen: Mohr.

Publisher's note Springer Nature remains neutral with regard to jurisdictional claims in published maps and institutional affiliations.

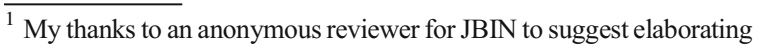
on this point.
} 